\title{
Editorial
}

Pensar en Movimiento:

Revista de Ciencias del Ejercicio y la Salud ISSN 1659-4436

Vol. 11, No. 1, pp. 1-3

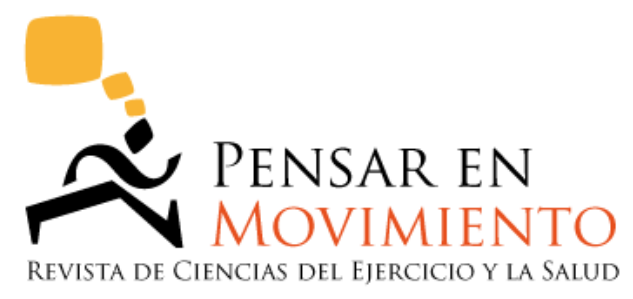

\section{DISCURSO INAUGURAL DEL XIX SIMPOSIO INTERNACIONAL DE CIENCIAS DEL DEPORTE, EL EJERCICIO Y LA SALUD}

\author{
Auditorio de la Ciudad de la Investigación \\ Universidad de Costa Rica \\ Lunes 6 de mayo de 2013
}

\begin{abstract}
(Agradezco al Dr. Henning Jensen por facilitarnos la transcripción de su discurso para incluirlo como editorial de este número de la revista -Luis Fernando Aragón V., Ph.D., FACSM, Director, Pensar en Movimiento).
\end{abstract}

Muy buenas tardes.

Para la Universidad de Costa Rica es un placer y un honor ser anfitriona del XIX Simposio Internacional en Ciencias del Deporte, el Ejercicio y la Salud.

En los últimos años, hemos atestiguado el dinamismo y la innovación de este ámbito académico, la transformación de su objeto de estudio y el enriquecimiento de sus perspectivas y métodos de análisis. Esto es resultado de la confluencia y el diálogo entre diferentes disciplinas, lo cual ha hecho posible la construcción de un conocimiento científico más complejo sobre la actividad física y el deporte, algo que sin duda se evidencia en el programa de conferencias y actividades de este Simposio.

Partiendo de la comprensión de la persona como unidad biopsicosocial, las Ciencias de la Salud, la Didáctica y la Psicología, entre otras áreas científicas, han encontrado un objeto de estudio común en los procesos y fenómenos asociados con la práctica de la actividad física y el deporte. Las líneas de investigación en desarrollo son muchas y muy diversas, sea desde una perspectiva más técnica de la corporalidad, o bajo la comprensión de la actividad física como acción comunicativa o de expresividad lúdica.

El deporte de hoy es un fenómeno sociocultural, producto del desarrollo histórico social en la modernidad, del cambio en los intereses de la sociedad respecto a la salud, la 
estética, el ocio y la competencia. En su sentido más amplio, esta comprensión del deporte está relacionada con el cambio social, los cambios de la ciencia, del panorama saludenfermedad, y de los ideales de corporalidad e individualidad. Por ello, es importante acompañar la investigación y la práctica profesional, con la reflexión sobre estos cambios, concepciones e ideales; es decir, con el análisis de los contextos ideológicos donde se inscriben el deporte y el ejercicio, que influyen sobre los motivos para su práctica y en las formas de organización de la actividad.

Actualmente, cuando se habla de deporte y ejercicio, se agrupan actividades y vivencias muy distintas, poblaciones y tipos de organización también diversos, que responden a intereses y necesidades particulares. Han surgido nuevas prácticas deportivas y nuevos grupos participan del deporte, personas de todas las edades, género, origen étnico o socioeconómico, cada una con condiciones físicas, psicológicas y sociales particulares.

Desde esa diversidad, el deporte y el ejercicio deben comprenderse como una experiencia o un estilo de vida que se construye. Por ello, la promoción de estas actividades debería tener más presencia dentro de las políticas sociales. No solo porque sean un elemento necesario para el desarrollo de programas de prevención de enfermedad y de promoción de la salud, sino también porque, a través suyo, se pueden cumplir objetivos educativos para el desarrollo comunitario. Por ejemplo, al facilitar procesos de integración social que puedan contribuir a desarrollar la solidaridad, la cooperación, el respeto y el trabajo en equipo para la solución de conflictos. Actitudes y formas de vinculación que fortalecen la convivencia dentro de la complejidad de nuestras sociedades.

Esta comprensión nos lleva a reflexionar sobre el modelo de sociedad al cual aspiramos. Porque para experimentar una salud integral se requiere un desarrollo urbano que estimule el ejercicio y sea propicio para la práctica del deporte, que ofrezca la seguridad necesaria para movernos en comunidad, con el respeto debido al medio ambiente y los recursos naturales. El diseño de los espacios públicos debe pensarse con el fin de ofrecer mejores oportunidades para vivenciar la movilidad humana y desarrollar estilos de vida sana. Nuestras ciudades exigen la recuperación de espacios para peatones y deportistas, requieren dar vitalidad a los puntos de encuentro social donde se fortalece la experiencia de comunidad.

Sin duda, las formas de interacción a través del movimiento humano continuarán transformándose junto con las sociedades a lo largo del siglo XXI. Un enfoque científico amplio y transdisciplinario será el adecuado para responder a los desafíos presentes en el estudio del deporte, el ejercicio y la salud.

Para la Universidad de Costa Rica, y en especial para la Escuela de Educación Física y Deportes, este Simposio es una oportunidad excepcional para fortalecer los vínculos 
internacionales y multidisciplinarios, intercambiar experiencias y conocimientos, como base para consolidar nuestras líneas y proyectos de investigación en este campo, así como para establecer nuevas opciones de trabajo.

Bienvenidos y bienvenidas. Reciban mis mejores deseos para las actividades y diálogos de los próximos días.

Muchas gracias.

Henning Jensen Pennington, Ph. D. Rector, Universidad de Costa Rica

\section{(c) (i) $\ominus$}

Esta obra está bajo una

licencia Creative Commons Atribución-NoComercial-SinDerivadas 3.0 Costa Rica 